4. Sundt TM, Zehr KJ, Dearani JA, Daly RC Mullany CJ, McGregor CG, et al. Is early anticoagulation with warfarin necessary after bioprosthetic aortic valve replacement? J Thorac Cardiovasc Surg. 2005;129:1024-31

5. Aramendi JI, Mestres CA, Martinez-Leon J, Campos V, Munoz G, Navas C. Triflusal versus oral anticoagulation for primary prevention of thromboembolism after bioprosthetic valve replacement (TRAC): prospective, randomized, cooperative trial. Eur J Cardiothorac Surg. 2005;27: 854-60.

doi:10.1016/j.jtcvs.2010.05.006

\section{REPORTING OF MORTALITY ASSOCIATED WITH PEDIATRIC AND CONGENITAL CARDIAC SURGERY}

To the Editor:

We congratulate Furck and colleagues ${ }^{1}$ for their excellent analysis of outcomes after the Norwood operation in patients with hypoplastic left heart syndrome, as described in their recent publication. However, we are concerned that the authors have reported the rate of mortality using a nonstandard strategy for this type of reporting. Furck and colleagues reported a 30-day mortality of $2.5 \%$ for the last 3 years. They stated that "Death after this period and until the subsequent palliative surgery, regardless of whether in or out of the hospital, was defined as interstage mortality." They reported interstage mortality of $15 \%$. This manner of reporting of outcomes is not consistent with standardized reporting strategies. It can be potentially misleading and can create unrealistic expectations among referring physicians, caregivers, and families.

Collaborative international efforts have resulted in the establishment of standardized methodologies for the reporting of mortality and morbidity associated with pediatric and congenital cardiac surgery., ${ }^{2,3}$ Operative mortality is defined as any death, regardless of cause, occurring (1) within 30 days after surgical intervention in or out of the hospital and (2) after 30 days during the same hospitalization subsequent to the operation. Thus operative mortality includes all deaths that occur during the initial hospitalization. Logically, interstage mortality encompasses all deaths that occur after the period of time included in operative mortality but before the stage 2 operation. Thus all mortality during the initial hospitalization should be classified as operative mortality and not interstage mortality.

The most recent analysis of the Society of Thoracic Surgeons Congenital Heart Surgery Database documents discharge mortality of $18.7 \%$ (447/ 2395 patients) after the Norwood (stage I) operation. ${ }^{4}$ By reporting only 30 -day mortality and classifying deaths that occur after 30 days but during the initial hospitalization as interstage mortality, the authors have used a methodology not consistent with standardized methodologies of outcome reporting. If an author wishes to explore other means of presentation, one would assume that it would be done with a degree of emphasis that was not apparent in this article. We believe that the use of standard reporting strategies for mortality is crucial when reporting the outcomes after pediatric and congenital cardiac surgery.

Richard A. Jonas, $M D^{a}$ Jeffrey P. Jacobs, $M D^{b}$

Marshall L. Jacobs, $M D^{c}$

Constantine Mavroudis, $M D^{c}$

${ }^{a}$ Department of Cardiac Surgery Children's National Heart Institute Children's National Medical Center Washington, $D C$

${ }^{b}$ Chair, STS Congenital Heart Surgery

Database Task Force

Surgical Director of Heart

Transplantation and ECMO

The Congenital Heart Institute of Florida (CHIF)

Department of Surgery University of South Florida College of Medicine

All Children's Hospital Children's Hospital of Tampa Cardiac Surgical Associates of Florida $(\mathrm{CSAoF})$

St Petersburg and Tampa, Fla ${ }^{c}$ Center for Pediatric and Congenital
Heart Diseases

Department of Pediatric and Congenital Heart Surgery Cleveland Clinic Foundation

Cleveland, Ohio

\section{References}

1. Furck AK, Uebing A, Hansen JH, Scheewe J, Jung O, Fischer G, et al. Outcome of the Norwood operation in patients with hypoplastic left heart syndrome: a 12-year single-center survey. J Thorac Cardiovasc Surg. 2010;139: $359-65$

2. Jacobs JP, Mavroudis C, Jacobs ML, Maruszewski B, Tchervenkov CI, Lacour-Gayet FG, et al. What is operative mortality? Defining death in a surgical registry database: a report from the STS Congenital Database Task Force and the Joint EACTS-STS Congenital Database Committee. Ann Thorac Surg. 2006;81: 1937-41

3. Jacobs JP, Jacobs ML, Mavroudis C, Maruszewski B, Tchervenkov CI, Lacour-Gayet FG, et al. What is operative morbidity? Defining complications in a surgical registry database: a report from the STS Congenital Database Task Force and the Joint EACTS-STS Congenital Database Committee. Ann Thorac Surg. 2007;84:1416-21.

4. Jacobs JP, Jacobs ML, Mavroudis C, Lacour-Gayet FG, Tchervenkov CI. Executive summary: the Society of Thoracic Surgeons congenital heart surgery database-Eleventh Harvest-(July 1, 2005-June 30, 2009). The Society of Thoracic Surgeons (STS) and Duke Clinical Research Institute (DCRI), Duke University Medical Center, Durham, NC; Fall 2009 Harvest.

doi:10.1016/j.jtcvs.2010.04.034

\section{Reply to the Editor:}

We thank Jonas and his colleagues for their interest in our study and for drawing our attention to the definition of operative mortality. ${ }^{1}$

During the review process of the manuscript, we offered to recalculate our data on mortality of the Norwood operation according to the definition of The Society of Thoracic Surgeons Congenital Database Taskforce and the Joint EACTS-STS Congenital Database Committee, ${ }^{2}$ but as we gave data on both 30-day mortality and interstage mortality, we were allowed to leave the data as presented.

However, we agree with Jonas and colleagues that the way of reporting operative mortality should be consistent to simplify comparison between groups. We, therefore, recalculated 


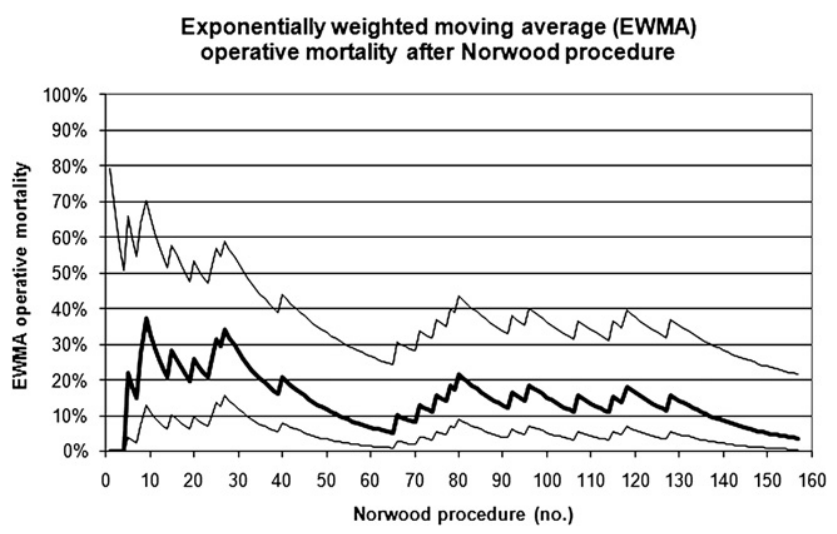

FIGURE 1. Operative mortality after the Norwood procedure. Exponentially weighted moving average $(E W M A)$ with $95 \%$ confidence intervals.

operative mortality adhering to the proposed definition and report that new information here:

Operative mortality of the Norwood procedure for hypoplastic left heart syndrome (death within 30 days after surgery in or out of the hospital and after 30 days during the same hospitalization subsequent to the operation) decreased from $21.1 \%$ during the first 3 years to $4.9 \%$ during the last 3 years of the reported 12-year period. Accordingly, the exponentially weighted moving average of operative mortality after the 157 Norwood procedures fell to $3.58 \%$ (Figure 1 ).

Interstage mortality, accordantly defined as all deaths that occurred after the 30-day period or after discharge from hospital after the Norwood operation but before the subsequent hemiFontan operation, could be reduced with introduction of our home surveillance program from $13.2 \%$ to $0 \%$.

As recalculations changed our data only minimally, we hope that the readers appreciate that we did not try to mislead anyone or to create unrealistic expectations among referring physicians, caregivers, and families but rather honestly presented our institutional experience with the Norwood operation for children with hypoplastic left heart syndrome.

A. K. Furck, $M D$

A. Uebing, $M D$

J. H. Hansen, $M D$
J. Scheewe, $M D$

H. H. Kramer, $M D$

Department of Pediatric Cardiology

University of Schleswig-Holstein

Pediatric Cardiology/Intensive Care Kiel, Schleswig-Holstein, Germany

\section{References}

1. Furck AK, Uebing A, Hansen JH, Scheewe J, Jung O, Fischer G, et al. Outcome of the Norwood operation in patients with hypoplastic left heart syndrome: a 12-year single-center survey. J Thorac Cardiovasc Surg. 2010;139:359-65.

2. Jacobs JP, Mavroudis C, Jacobs ML, Maruszewski B, Tchervenkov CI, Lacour-Gayet FG, et al. What is operative mortality? Defining death in a surgical registry database: a report from the STS Congenital Database Task Force and the Joint EACTS-STS Congenital Database Committee. Ann Thorac Surg. 2006;81: 1937-41.

doi:10.1016/j.jtcvs.2010.05.023

\section{COMPARABLE PATENCIES OF THE RADIAL ARTERY AND RIGHT INTERNAL THORACIC ARTERY OR SAPHENOUS VEIN BEYOND 5 YEARS: RESULTS FROM THE RADIAL ARTERY PATENCY AND CLINICAL OUTCOMES TRIAL \\ To the Editor:}

A recent article by Hayward and colleagues ${ }^{1}$ presents important data regarding the long-term patency and clinical outcome of the radial artery (RA), right internal thoracic artery (ITA), and saphenous vein (SV) when used as conduits in patients undergoing coronary artery bypass grafting. The main purpose of the authors' trial was to identify the place of the RA in the hierarchy of options available to supplement the ITA to the left anterior descending coronary artery. Patients were monitored at defined time points (mean, 5.5 years), with the results leading the authors to suggest that the RA or free ITA are equally satisfactory in younger patients and that RA and SV grafts produce similar angiographic outcomes in older patients.

Two points are of particular interest. First, the authors found a striking increase in vein graft patency compared with that seen in previously published studies. Second, the authors recognize the importance of atraumatic harvesting of both the RA and SV in achieving improved graft performance. These results were presented at the 2008 American Association for Thoracic Surgery Meeting, where some relevant points were raised. In particular, the authors were asked whether any of the veins in the study were harvested endoscopically. The response was that they were not because endothelial integrity might have been affected by this method, adding "These veins were all taken in a shamelessly open no-touch manner.'

It is not clear which no-touch method was used, but if it was the same or similar to that used routinely in our unit in Örebro, the SV would have been removed without distension and with its surrounding cushion of tissue intact. ${ }^{2}$ This method provides a graft with a patency rate comparable with that of the ITA $^{3}$ and preserves normal vessel structure that is very different in appearance from that of SV grafts prepared conventionally (Figure 1). We believe that the vasa vasorum plays an important role in the improved patency of SVs harvested with surrounding tissue because medial blood flow is restored through this network of nutrient microvessels after completion of graft insertion and removal of vascular clamps. This does not occur in conventionally harvested veins in which the 